\title{
HER3 and downstream pathways are involved in colonization of brain metastases from breast cancer
}

Leonard Da Silva 1,2,3, Peter T Simpson ${ }^{1,2}$, Chanel E Smart ${ }^{1,2}$, Sibylle Cocciardi ${ }^{2}$, Nic Waddell ${ }^{2}$, Annette Lane ${ }^{1}$, Brian J Morrison ${ }^{2,4}$, Ana Cristina Vargas ${ }^{1}$, Sue Healey², Jonathan Beesley ${ }^{2}$, Pria Pakkiri ${ }^{1}$, Suzanne Parry ${ }^{1,2}$, Nyoman Kurniawan ${ }^{5}$, Lynne Reid ${ }^{1,2}$, Patricia Keith ${ }^{1,2}$, Paulo Faria ${ }^{7,6}$, Emilio Pereira $^{8}$, Alena Skalova ${ }^{9}$, Michael Bilous ${ }^{10}$, Rosemary L Balleine ${ }^{11}$, Hongdo Do ${ }^{12}$, Alexander Dobrovic ${ }^{12}$, Stephen Fox ${ }^{12}$, Marcello Franco ${ }^{3}$, Brent Reynolds ${ }^{13,16}$, Kum Kum Khanna ${ }^{14}$, Margaret Cummings ${ }^{1,14}$, Georgia Chenevix-Trench², Sunil R Lakhani ${ }^{1,2,15^{*}}$

\begin{abstract}
Introduction: Metastases to the brain from breast cancer have a high mortality, and basal-like breast cancers have a propensity for brain metastases. However, the mechanisms that allow cells to colonize the brain are unclear.

Methods: We used morphology, immunohistochemistry, gene expression and somatic mutation profiling to analyze 39 matched pairs of primary breast cancers and brain metastases, 22 unmatched brain metastases of breast cancer, 11 non-breast brain metastases and 6 autopsy cases of patients with breast cancer metastases to multiple sites, including the brain.
\end{abstract}

Results: Most brain metastases were triple negative and basal-like. The brain metastases over-expressed one or more members of the HER family and in particular HER3 was significantly over-expressed relative to matched primary tumors. Brain metastases from breast and other primary sites, and metastases to multiple organs in the autopsied cases, also contained somatic mutations in EGFR, HRAS, KRAS, NRAS or PIK3CA. This paralleled the frequent activation of AKT and MAPK pathways. In particular, activation of the MAPK pathway was increased in the brain metastases compared to the primary tumors.

Conclusions: Deregulated HER family receptors, particularly HER3, and their downstream pathways are implicated in colonization of brain metastasis. The need for HER family receptors to dimerize for activation suggests that tumors may be susceptible to combinations of anti-HER family inhibitors, and may even be effective in the absence of HER2 amplification (that is, in triple negative/basal cancers). However, the presence of activating mutations in PIK3CA, HRAS, KRAS and NRAS suggests the necessity for also specifically targeting downstream molecules.

\section{Introduction}

Among women with breast cancer, $30 \%$ to $40 \%$ will develop metastatic disease. The natural history of metastatic breast cancer to the brain is of symptomatic disease in $10 \%$ to $20 \%$ of these patients and a dismal mean survival of six months following diagnosis [1,2]. Associations with younger age, p53 positivity, estrogen receptor

\footnotetext{
* Correspondence: s.lakhani@uq.edu.au

${ }^{1}$ Molecular \& Cellular Pathology, The University of Queensland Centre for Clinical Research, \& School of Medicine, Building 918/B71, RBWH complex, Brisbane, 4029, Australia
}

(ER) negative and epidermal growth factor receptor 1 (EGFR) and two (HER2) positive cancers have been reported [3-5]. The epidermal growth factor receptor family comprises four receptors, HER1 to 4 . Upon activation, hetero or homo-dimerization occurs, followed by phosphorylation of specific tyrosine residues in the intracellular domain, stimulating signaling cascades mediated mainly by AKT and MAPK and the regulation of cell proliferation, angiogenesis, migration and survival $[6,7]$. 
Basal-like tumors are generally high grade, negative for ER, progesterone receptors (PgR) and HER2 (that is, triple negative) [8]. The current dogma would predict that these tumors are unlikely to respond to endocrine and trastuzumab-based therapy and no targeted therapy is currently available, although clinical trials are ongoing [8]. Despite being node negative, a proportion of patients subsequently present with distant metastases, particularly to the brain $[9,10]$

Using autopsy records of breast cancer patients, Paget [11] demonstrated a non-random pattern of metastatic spread. This suggested that tumor cells (the seed) could have a specific affinity for the microenvironment of certain organs (the soil). In agreement, animal models demonstrate that particular sets of genes can increase the potential of breast cancer cell lines to colonize specific distant sites, for example, bone, lung [12,13]; and brain [14,15].

The cancer mutatome is very complex, with more than 140 CAN genes identified which are mutated at a significant frequency in cancer [16,17]. The genomic landscape of breast cancer is also very complex and heterogeneous, with different subgroups of tumours (luminal, basal, HER2) harboring different types and patterns of mutations [18]. There is also evidence that breast cancer cell lines with a basal phenotype have a higher frequency of mutations in BRAF, KRAS, and HRAS than luminal breast cancer cell lines [19-21].

We have analyzed a relatively large and rare set of human tumors to elucidate the mechanisms involved in colonization of the brain. Samples studied involved matched pairs of primary breast cancer and brain metastases, unmatched brain metastases, non-breast brain metastases and autopsy cases of breast cancer patients with metastases to multiple sites, including the brain. We provide evidence of increased activation of HER3 and downstream pathway molecules in brain metastases from breast cancer and suggest that the inhibition of HER family receptors, even in the absence of HER2 gene amplification (for example, triple negative/basal cancers), could play a significant role in the management of patients with brain metastases from breast cancer. In addition, we demonstrated the possible fallacies of this approach without considering the presence of somatic activating mutations in downstream molecules [22-24].

\section{Materials and methods}

Additional detailed methodologies (see Additional file 1 ). The study was approved by the local research ethics committees under the project number UQ2005000785 and RBHW 2005/22.

\section{Clinical samples}

All human clinical samples studied were available as formalin fixed-paraffin embedded (FFPE) tumor blocks.
Cohorts collected were: i) 39 matched pairs of primary breast cancer and brain metastases; ii) 22 unmatched brain metastases from breast cancer; iii) 11 brain metastases from non-breast sites (one melanoma, one colorectal, six lung, one prostate and two renal cell carcinomas); and iv) 26 tumor samples (primary breast cancer and metastases to multiple sites, including brain) from six autopsy cases of patients who died of metastatic breast cancer (the primary breast cancer from one case was not available). The tumors were reviewed by three pathologists (LDS, MC and SRL) and analyzed by immunohistochemistry and chromogenic in situ hybridization $(\mathrm{CISH})$ on tissue microarrays. Immunohistochemistry for EGFR, HER2, HER3, HER4, CD44 and CD24 was also done on whole sections.

\section{Gene expression analysis}

RNA was extracted from FFPE samples and the expression of 512 cancer related genes was analyzed using the DASL assay (cDNA-mediated annealing, selection extension and ligation, Illumina Inc., San Diego, California, USA) [25]. All data and protocols for DASL analysis can be found at the Gene Expression Omnibus repository (Accession number GSE14690) (see also additional file 1). Real-time PCR using $\mathrm{TaqMan}^{\circ}$ gene expression assays (Applied Biosystems, Inc, Carlsbad, California, USA ) and immunohistochemistry were performed to validate the expression of specific genes.

\section{Somatic mutation analysis}

Twelve matched pairs of primary breast tumors and corresponding brain metastases, nine non-breast brain metastases and 26 tumor samples from the six autopsy cases were subjected to primer extension and MALDITOF mass spectrometry using the OncoCarta ${ }^{\circ}$ Panel Assay v1.0 (Sequenom Inc., San Diego, California, USA) of 238 mutations in 19 oncogenes [26]. All mutations in samples for which there was sufficient DNA remaining were validated by High Resolution Melt (HRM) [27] analysis, iPLEX (using newly designed PCR and extension primers that differed from the OncoCarta primers), repeat OncoCarta analysis, and/or direct sequencing if the Mutant Allele Proportion (MAP) was $>30 \%$ (Table 1 and Additional file 2, Table S2). In addition, we were able to validate the EGFR E746_A750del mutation in four cases with a mutation-specific antibody [28].

\section{Results}

\section{Clinical and pathological features}

The median age at diagnosis was 48.5 years and the median time for the development of brain metastasis was 3.5 years. All but one of the series of primary breast cancers and all brain metastases were grade 3 invasive ductal carcinomas-no specific type (IDC-NST) [29]. The 


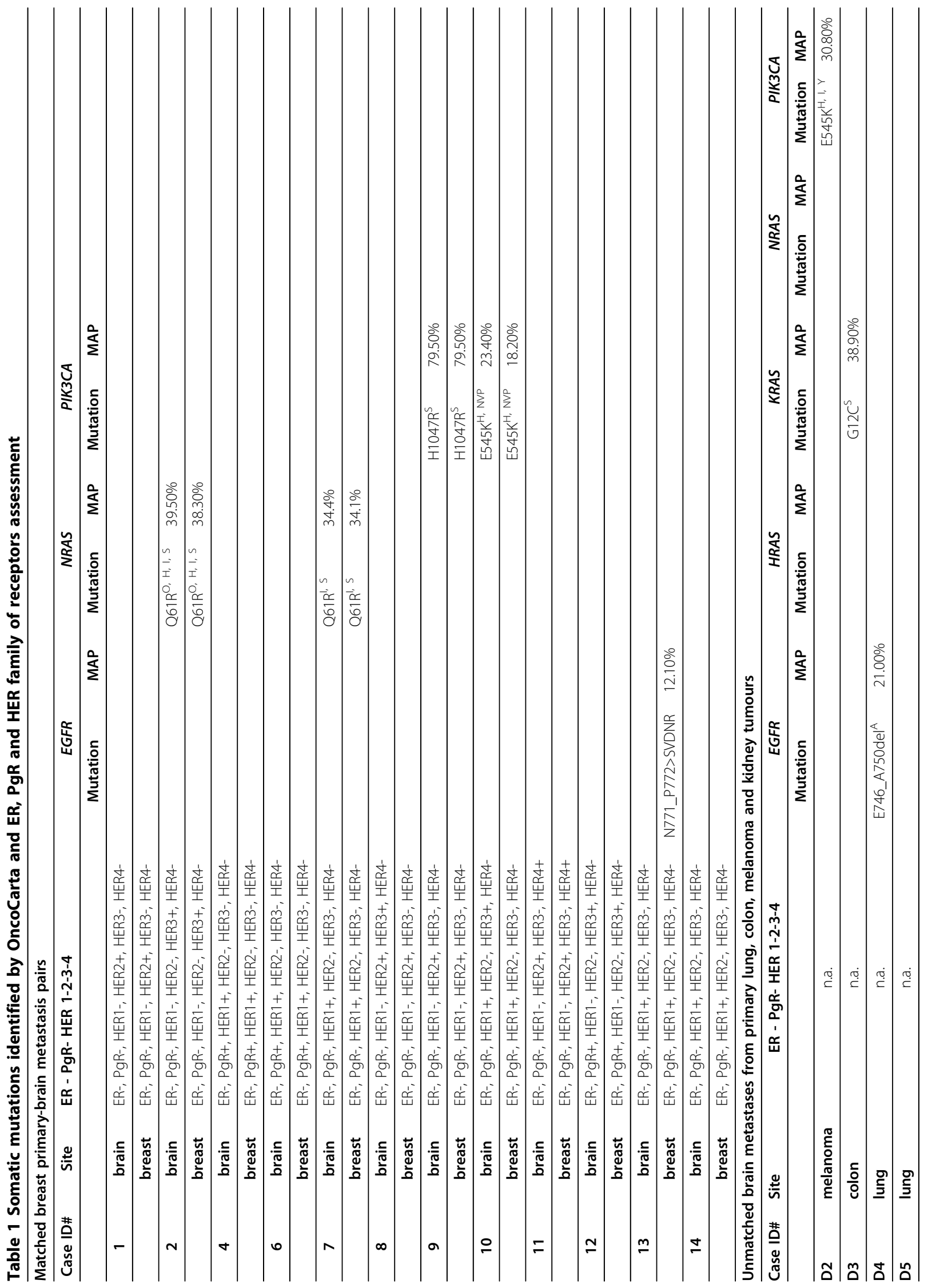


remaining tumor pair was a grade 2 mucinous carcinoma. The autopsy samples comprised four grade 3 and one grade 2 IDC-NST.

\section{ER, PgR, HER2, 'Basal' markers and stem cell markers (non-autopsy cases)}

Immunohistochemistry data are summarized in Figure 1A, B (see also additional file 2, Table S1 and Figure S1). It was noteworthy that $60 \%$ and $76 \%$ of the tumors were negative for ER and PR, respectively, with complete concordance between primary and metastases. Seventy-seven percent $(77 \%)$ and $81 \%$ of the unmatched brain metastases were also ER and PR negative, respectively. Twenty percent (20\%) and $19 \%$ of the primary breast tumors and metastases, respectively, had correlated over-expression of HER2 (3+ staining) and all of these showed gene amplification using CISH. Twenty percent $(20 \%)$ of the unmatched metastases were also HER2+. Fifty-six percent (56\%) of the primary tumors and $48 \%$ of the matched metastases were triple negative and of these, $60 \%$ were positive for at least one of the basal markers respectively (CK14, CK5/6, CK17, EGFR and SMA). Overall, $54 \%$ of the primary and $60 \%$ of the metastases were of basal phenotype (irrespective of ER, PR and HER2 status), confirming enrichment in this cohort over the normal distribution in breast cancer [8]. Noteworthy, EGFR staining was seen mainly in the periphery of the tumor where there was contact with nonneoplastic brain parenchyma [30]. A higher proportion of brain metastases had a putative stem cell-like phenotype $\left(\mathrm{CD} 44^{+} / \mathrm{CD} 24^{-}\right)$compared to the primaries, $55 \%$ versus $25 \%$, (Figure 1A). Fifty-one percent (51\%) of the primary tumors had a Ki-67 index higher than $10 \%$ in contrast to matched and unmatched metastases that had $86 \%$ and $85 \%$ of samples with index higher than $10 \%$.

\section{Gene expression profiling}

The availability of good quality RNA and stringent filtering of the DASL data yielded gene expression profiling data on $37 / 61$ brain metastases from breast cancer (15/ 39 from matched pairs and 22/22 from unmatched metastases) and 15 matched primaries. Unsupervised analysis highlighted a strong similarity between primary tumors and their matched metastases (Figure 2A). Only 20 genes were differentially expressed between the matched primaries and metastases. This may be a consequence of the overall strong similarity between primaries and metastases [31] coupled with the sample size $(\mathrm{n}=30)$ and number of genes analyzed $(\mathrm{n}=512$ cancer genes in the DASL panel) [32]. Comparison between primaries and all metastases (matched and unmatched) identified 27 statistically significant, differentially expressed genes (Figure 2B). Supplementary Figure 2 


\section{Immuhistochemical profile}

A

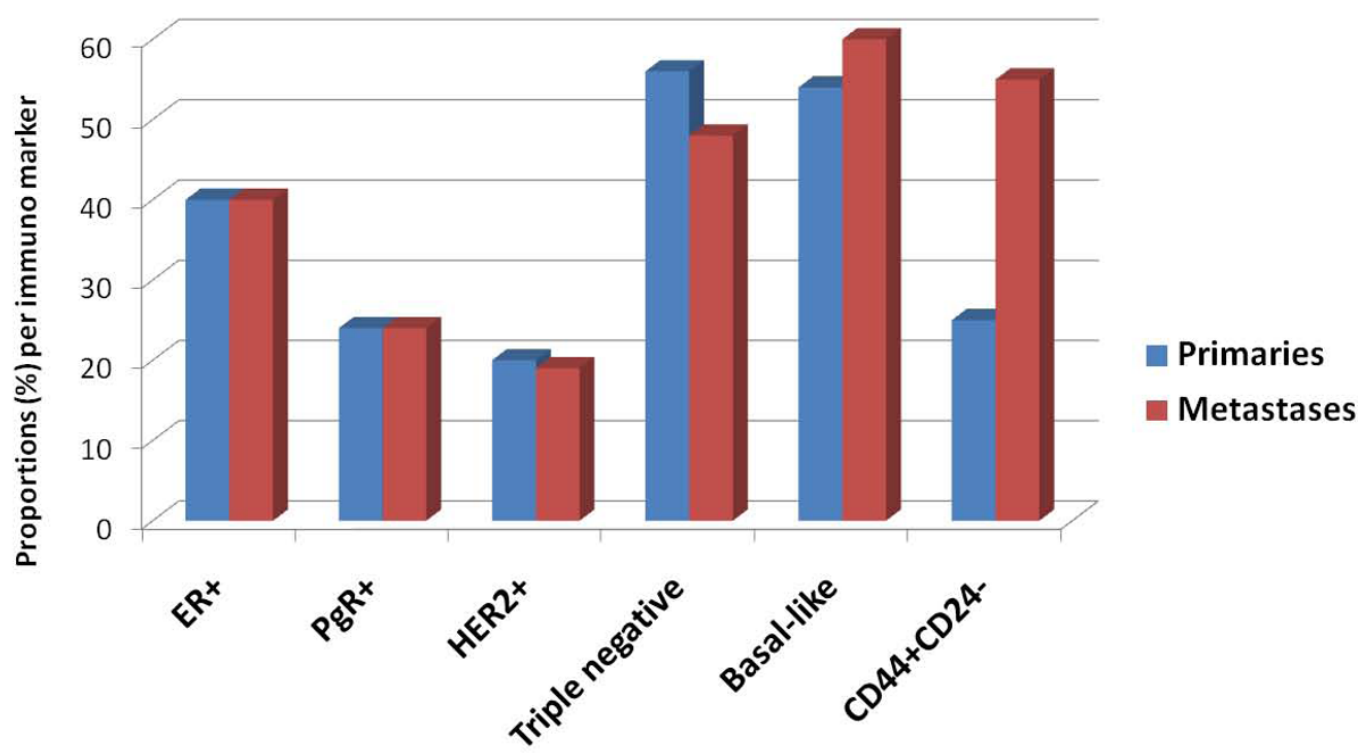

B

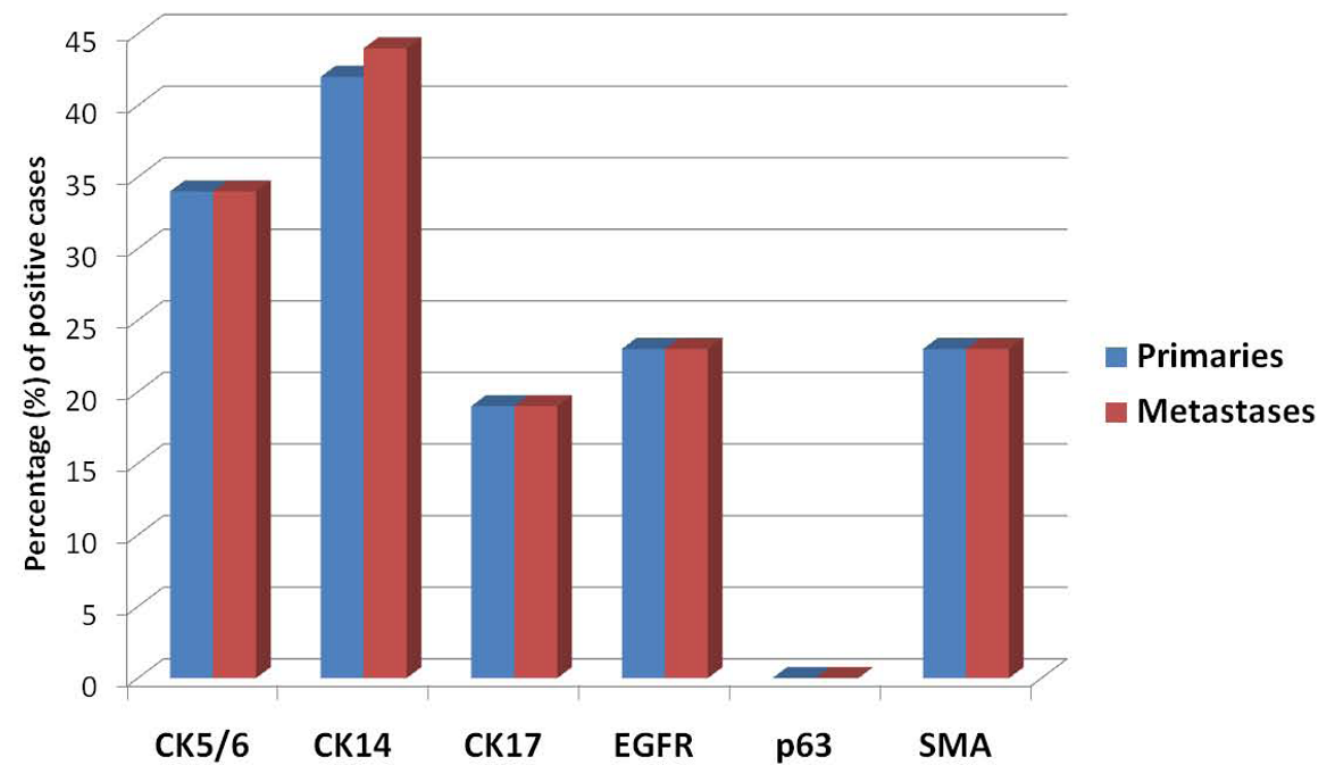

Figure 1 Immunohistochemical profile of primary breast and brain metastases. A - Immunohistochemical analysis of matched primary breast and brain metastases. The graph depicts percentages of positive cases in each category. ER and PR were considered positive when $>10 \%$ cells showed staining, HER2 was considered positive when IHC showed 3+ staining (>30\% positive cells) or CISH showed gene amplification. Triple negative tumors were negative for ER, PR and HER2. CD44+/CD24- immunohistochemistry was assessed on serial sections and positivity was expression in $>10 \%$ cells. B - Breakdown of basal markers. A tumor was regarded as basal if any of the following markers were positive (CK5/6, CK14, CK17, p63, SMA, and EGFR) with >10\% cells showed staining. 
A

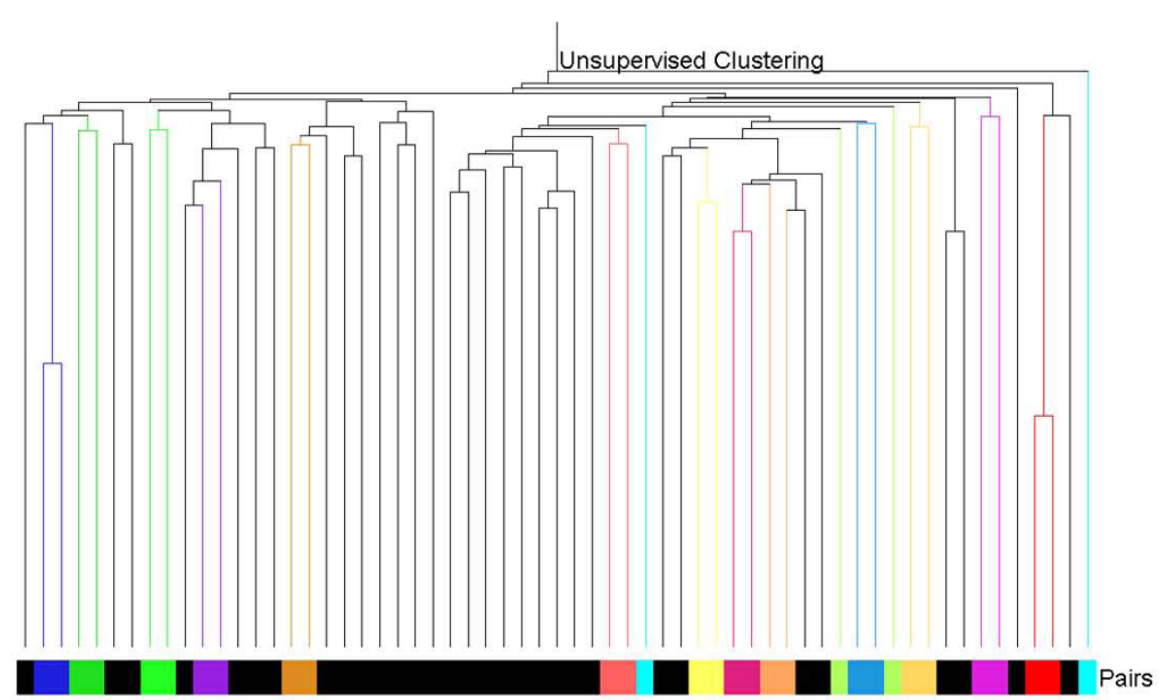

B

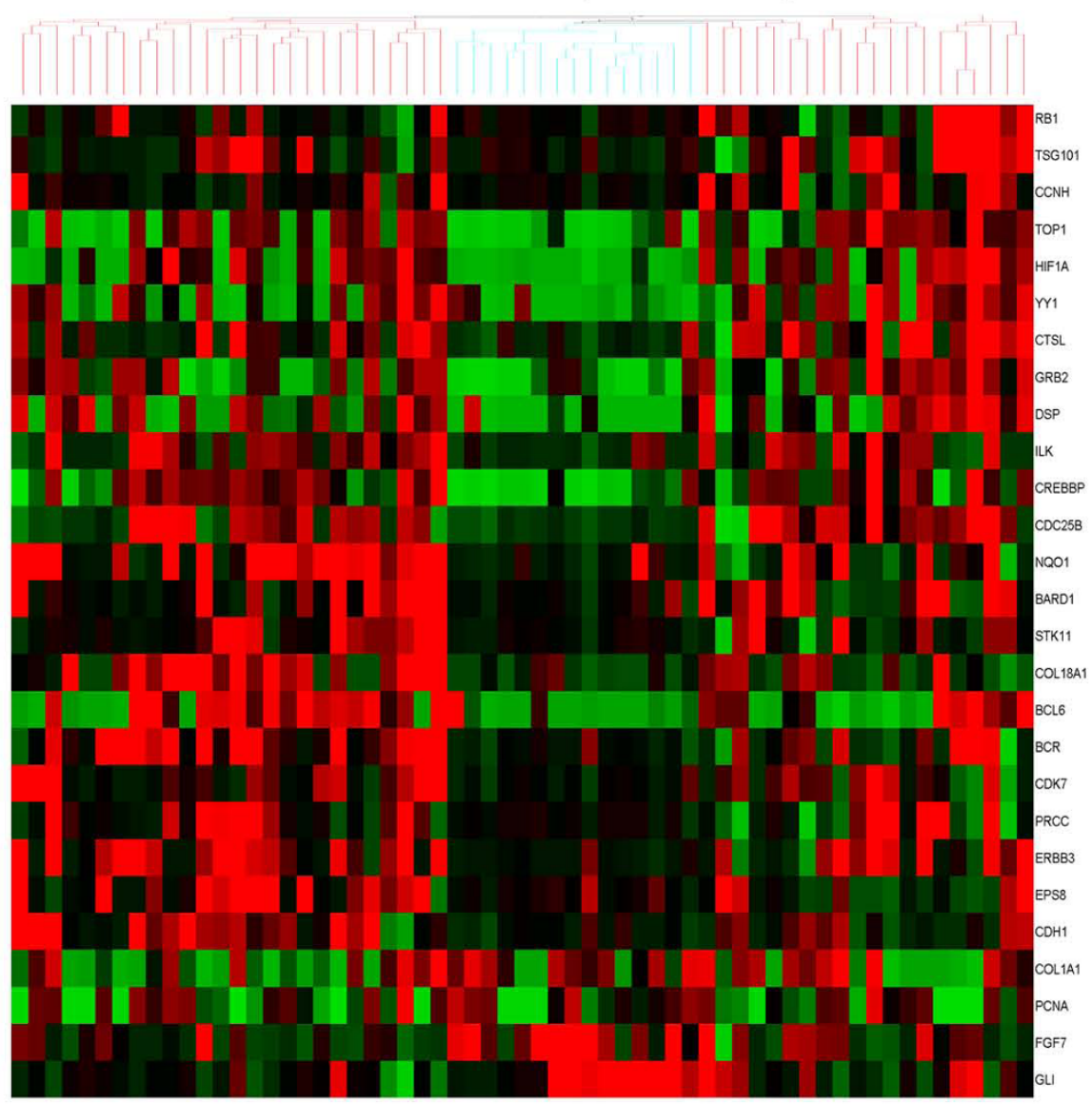

Figure 2 Gene expression profiling of brain metastases. A - Unsupervised hierarchical clustering of DASL gene expression data from 22 unmatched (black color bar) and 15 matched primary and brain metastases (other colors bars). Thirteen out of 15 matched samples are clustering together. B - Heatmap and dendogram showing clustering of the samples based on the 27 genes differentially expressed between primary tumors (blue line bar) and brain metastases (red line bar). 
(see Additional file 2, Figure S2) depicts principal component analysis showing good separation of the primaries and metastases using this 27-gene list. All 20 genes identified in the matched pair analysis were part of this 27-gene set. Among this 20-gene set, were HER3 and one of its downstream target molecules GRB2 [33], hypoxia related molecule HIF1-alfa, MAPKinase cascade related protein $C R E B B P$, cell cycle regulator $\mathrm{RB} 1$ and proliferation related genes $C C N H, C D K 7$ and $C D C 25 B$. Since the brain is rich in neuregulin $1[34,35]$ and this is a ligand for HER3, we hypothesized that the neuregulinHER3 activation was important in allowing breast cancer cells to colonize the brain.

\section{HER family receptors and downstream molecules expression}

HER3, EGFR, HER2, HER4 and HIF1-alfa expression was assessed using quantitative RT-PCR (see Additional file 2, Figure S3) in 12 matched breast/brain samples for which DASL data and RNA were available. Similar to the DASL data, 10 cases showed increased fold change by RT-PCR of HER3 gene expression relative to their matched primaries ranging from 1.12 to 5.8 and with an average of 2.4. Immunohistochemistry for HER3 was similar, showing positivity in $11 / 37(29.7 \%)$ of the primary tumors, $22 / 37$ (59\%) of the matched metastases and $13 / 21(62 \%)$ of the unmatched brain metastases $(P=0.019)$. In agreement, phosphorylated HER3 confirmed more frequent activation in the brain metastases, with positivity in $14 / 37$ (37\%) of the primary tumors, $24 / 37$ (64\%) of the matched metastases and 18/21 (85\%) of the unmatched brain metastases $(P=0.046)$ (see Additional file 2, Table S1 and Figure S1).

Immunohistochemistry for GRB2, HIF1-alfa and phosphorylated ERK1/2, JNK1/2, ERK5 and p38 also demonstrated increased activation in the metastases compared to the primary tumors; (see Additional file 2, Table S1 and Figure S1). In contrast, phosphorylated AKT was equally high in both the primaries and metastases (see Additional file 2, Table S1). Interestingly, the non-breast derived brain metastases showed similarly high activation of the MAPK pathway together with over-expression (3+ stain) of EGFR (in 9/11 (81\%) metastases (a prostate and one colon carcinoma did not) but in the absence of HER3 activation (0/11) (see Additional file 2, Table S1).

\section{Somatic mutation analysis}

OncoCarta analysis identified mutations in the brain metastases from primary breast cancers (non-autopsy cases) in NRAS (2/12 - 17\%), and PIK3CA (2/12 - 17\%) (Table 1 and Figure 3). Mutations were also identified in brain metastases from non-breast primaries in EGFR (3/ 9 - 33\%; two lung and one kidney), HRAS (1/9 - 11\%; lung), KRAS (2/9 - 22\%; one colon and one lung), NRAS (3/9 - 33\%; two lung and one kidney) and PIK3CA (2/9 - 22\%; one melanoma and one lung).

Mutant Allele Proportions (MAPs) ranged from 9\% to $80 \%$. All these mutations were validated by immunohistochemistry (using a specific antibody raised against the protein with the EGFR E746_A750del mutation) or sequencing except for one each in EGFR, HRAS (validated by iPLEX), NRAS and PIC3CA (validated by HRM), where the estimated mutant allele proportion was less than $15 \%$, and two in PIK3CA in which there was insufficient good quality DNA remaining to obtain sequence data. EGFR G719 S appeared to be found frequently by OncoCarta but could not be detected by iPLEX, using independent PCR and extension primers. The OncoCarta false-positive result appeared to be due to hairpin formation of the extension primer that occurred frequently when archival DNA was used as a template, and the yield was low.

Except for one EGFR mutation (Case \#13; Table 1), the same somatic mutations were observed in the brain metastases with similar MAPs as in the matched primary breast tumors. It was noteworthy that the four matched pairs harboring somatic mutation in NRAS or PIK3CA also overexpressed a member of the HER family. For example, matched pair \#2 had a mutation in NRAS and showed over-expression of HER3, matched pair \#7 had a mutation in NRAS and showed over-expression of HER1, matched pair \#9 had a mutation in PIK3CA and amplification of HER2 and matched pair \#10 had a mutation in PIK3CA and overexpression of HER1 (Table 1).

Among the autopsy samples of cases with primary breast cancer, we found mutations in EGFR in one liver and one lymph node metastases, and a mutation in PIK3CA in all the samples from one case, and in a liver metastasis from another (see Additional file 2, Table S2). One EGFR and one PIK3CA mutation could be verified by sequencing or immunohistochemistry but lack of good quality DNA, and additional mutation-specific antibodies, prohibited validation of the others. All the samples from one case had the same mutation at similar MAPs (PIK3CA H1074R in Patient \#2).

We identified HRAS and PIK3CA mutations in the basal breast cancer cell lines SUM 159 and BT20. The mutations with MAPs $>25 \%$ have been reported before [19,20]: HRAS G12 D (MAP 53.2\% in SUM159) and PIK3CA H1047L (MAP 50.0\% in SUM159) and P539R (MAP $43.8 \%$ in BT20) but we also identified HRAS Q61K at MAP 24.6\% in SUM159 and HRAS Q61K at MAP $14.1 \%$, and PIK3CA H1047R at MAP $44.4 \%$ in BT20. In addition, we were also able to show that all of the mutations with MAPs $>25 \%$ were present in mammospheres derived from these cell lines. 


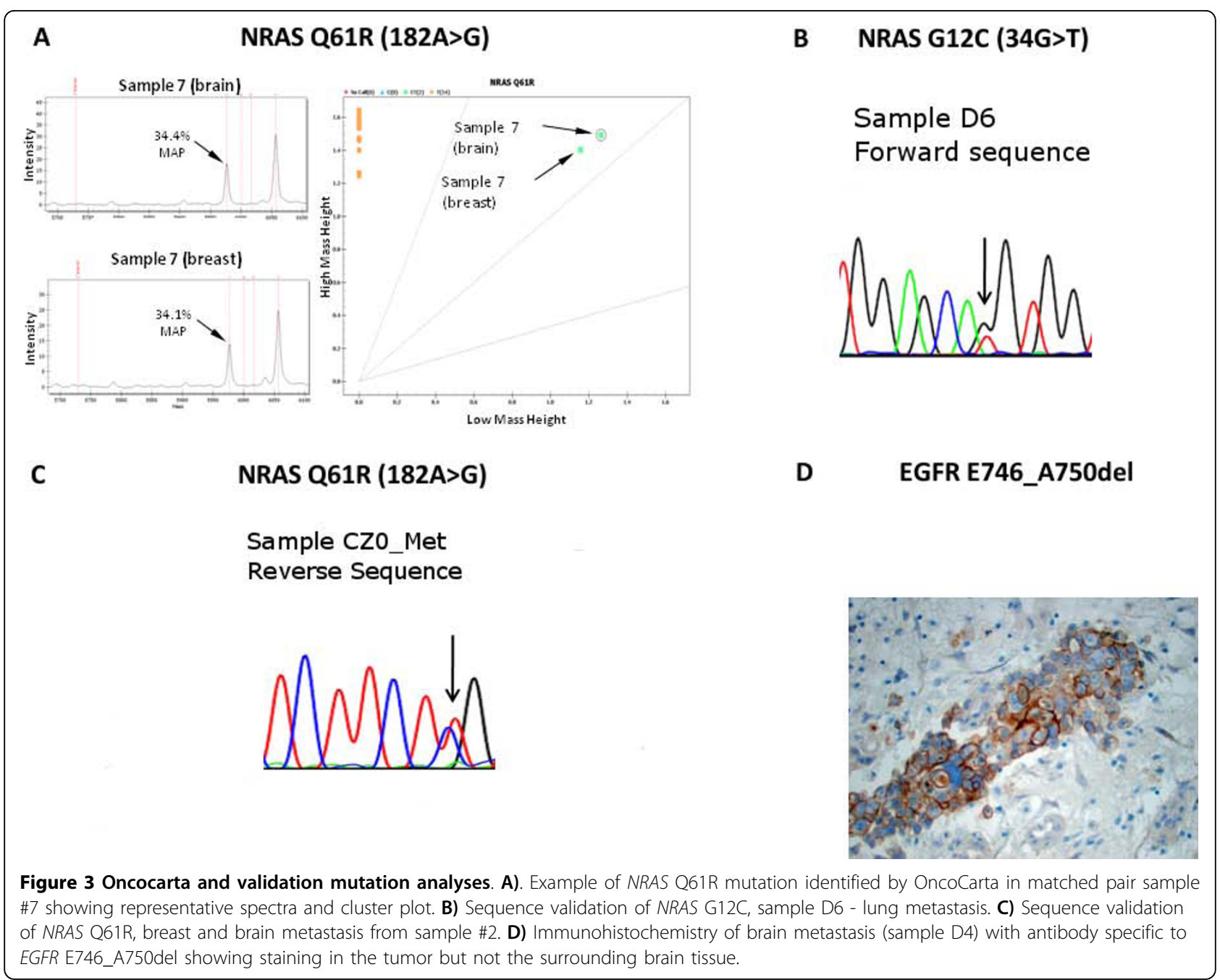

\section{Discussion}

We have collected a unique set of clinical material through collaborations with multiple institutions around the world and involving brain metastases which are rarely excised. The analysis of this resource has led to the development of hypotheses regarding the mechanisms of breast cancer colonization of the brain (Figure 4). The set of tumor samples is enriched for triple negative/ basal breast cancers which is consistent with the findings of an increased propensity for basal breast cancers to metastasize to the brain $[3,9,36]$. An association between CD44+/CD24- frequency and a basal tumor phenotype has already been reported [37] and interestingly we observed an increased frequency of CD44 +/CD24- cells in the brain metastases compared to their matched primaries. CD44+/CD24- cells have been reported to have stem cell properties and increased in vivo tumorigenicity [38] and the increased frequency seen in brain metastases may support this. Alternatively, this may reflect selection as a result of a high content of hyaluron, the ligand for $\mathrm{CD} 44$, within the brain microenvironment $[39,40]$. Hence, this could be an important factor in breast cancer colonization of the brain and therefore a potential axis for future therapeutic intervention [41].

In this study, brain metastases of breast cancer expressed all members of the HER family of tyrosine kinase receptors. HER2 was amplified and overexpressed in $20 \%$ of brain metastases, EGFR was overexpressed in $21 \%$ of brain metastases, HER3 was overexpressed in $60 \%$ of brain metastases and HER 4 was overexpressed in $22 \%$ of brain metastases and generally mutually exclusive (Table 1). Interestingly, HER3 expression was increased in breast cancer cells residing in the brain. Neuregulin 1, the ligand for this receptor, is abundantly expressed in the brain $[34,35]$ and is released by a variety of mechanisms including the presence of hypoxia [42]. Consistent with this, we observed the increased expression of HIF-1alfa in the brain metastases, likely to reflect the local hypoxic environment [43]. Increased 


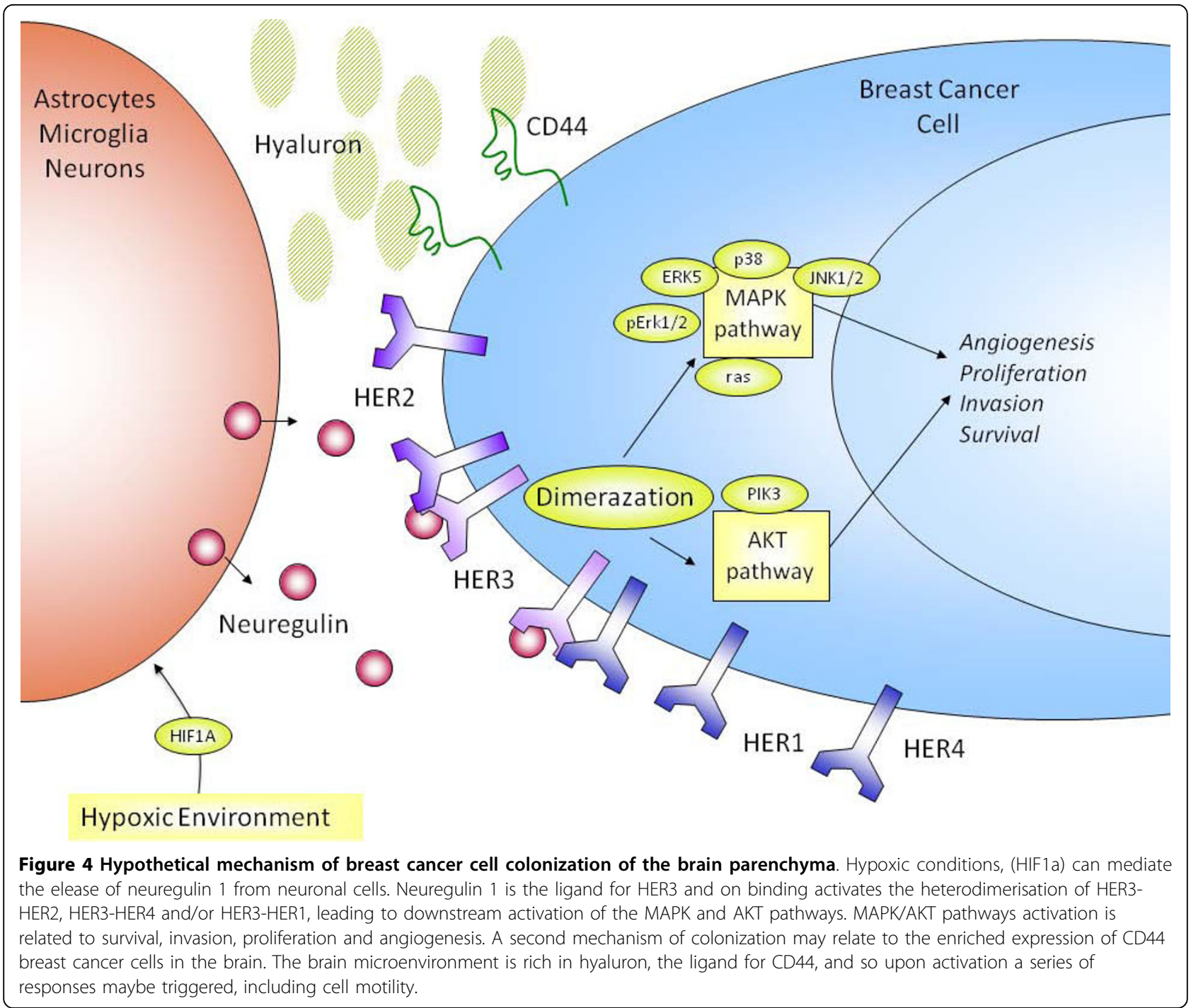

activation of both HER3 and downstream molecules (GRB2, ERK5, ERK1/2, JNK1/2, p38) was also observed in the brain metastases. These findings prompted us to hypothesize that neuregulin/HER3 activation is an important mechanism for breast cancer cell colonization of the brain (Figure 4). As a further support to this hypothesis, increased HER3 expression has also been reported in brain metastases of lung cancer [44].

We investigated whether this association was generic to all brain metastases and found activation of the MAPK pathway in all 11 non-breast metastases to the brain. Whilst HER3 was not activated in these tumors, 9/11 tumors showed over-expression of EGFR. It has recently been shown, using animal models, that EGFR ligands mediate breast cancer metastasis to the brain and that this was abrogated by the use of EGFR inhibitor cetuximab [14]. The combination of lapatinib and trastuzumab has been shown to have a synergistic, antiproliferative effect against ErbB2-positive breast cancer cells in vitro [45]. It is possible, therefore, that a combination of anti-HER therapies could be effective in the treatment of both breast and non-breast metastases to the brain.

In order to activate downstream signaling pathways, HER3 requires heterodimerization with other members of the HER family following binding by neuregulin [46] and even basal levels of the other HER proteins may be sufficient to participate in the activation of these pathways. Hence, combination therapy against the HER family, even in the absence of over-expression or amplification of HER2, may be of clinical benefit for a larger proportion of breast cancer patients such as those with HER2 negative disease. Recently, a study showed benefits for a small group of HER2-negative patients in the phase III National Surgical Adjuvant Breast and Bowel Project (NSABP) B-31 trial that were HER2 negative by 
FISH and had less than $3+$ staining intensity by HercepTest $^{\circ}$ (Dako, Carpinteria, CA, USA) [47]. Furthermore, another study suggested that the spectrum of patients who may benefit from trastuzumab-based therapies could be expanded to include patients with metastatic breast cancer without HER-2 amplification but who express transmembrane neuregulin, the ligand of HER3 [48]. It has also been reported in non-HER2 overexpressing xenograft models of prostate and breast cancer that pertuzumab, an inhibitor of HER3/HER2 heterodimerization, can inhibit tumor growth [49].

For the first time, we have identified somatic mutations in genes related to the AKT/MAPK signaling pathways, such as EGFR, PIK3CA, KRAS, HRAS and NRAS, in brain metastases of breast cancer and other types of cancer. In addition, we have analyzed multiple autopsy samples from six cases that had a primary breast cancer, and found additional EGFR and PIK3CA mutations in breast cancers that metastasized to various sites including the brain. Thus, simply targeting the HER family of receptors may not be sufficient for complete treatment response. This analysis highlights additional actionable targets [50] that may prove effective for the treatment of some brain metastasis, such as PI3 kinase inhibitors.

Taken together, these findings are striking and show another facet of the cell evolution landscape [51], highlighting the possibility of cancer cells resisting targeted treatment to molecules such as HER2 or EGFR by acquiring oncogenic mutations in downstream pathways. This has been shown in vitro with activating PIK3CA mutation [23] and herein we demonstrate an in vivo example of this possible scenario using human tumors. In another clinical angle, patients currently treated with the anti-EGFR monoclonal antibodies cetuximab and panitumumab can also acquire resistance to this therapy due to downstream mutations in the ras gene [24]. Interestingly, animal models have suggested that downstream NF-kappaB inhibitory drugs may play a role in the treatment of patients with defined mutations in KRAS [52].

Interestingly the Mutant Allele Proportion (MAP) was sometimes as low as $10 \%$. Such low proportion mutations, which would often be missed by direct sequencing could reflect the presence of stromal (or brain) contamination in the samples, tumor heterogeneity and amplification or deletion of the mutant or wild type alleles. However, the fact that the same MAP was often observed in both the primary and the brain metastasis, and in the multiple samples from an autopsy case, might suggest that these metastases were not seeded by a single cell but by groups of cells from the primary tumor. This has also been shown by next generation sequencing, whereby the mutant allele frequency for some mutations was similar between a basal-like primary breast cancer and its matched brain metastasis [53]. However, it is also evident that significant genomic evolution occurs during metastasis, since most mutations identified in this metastasis, and one from a primary lobular breast cancer, were more prevalent in the metastasis than in the respective primary tumours $[53,54]$

\section{Conclusions}

In conclusion, we provide evidence to support a role of HER3 and other HER family receptors in the ability of cancer cells to colonize the brain. The data are intriguing and support the possibility that tumors with low expression of HER2 may respond to trastuzumab, lapitinib or combinations of HER family receptor inhibitors since even basal levels may enhance the signaling through homo/hetero-dimerization of the other receptors. However, caution should be exercised because of the possible presence of downstream oncogenic mutations that may drive treatment resistance. These therapeutic modalities may therefore add another dimension to the treatment of triple negative and basal-like cancers where currently, no targeted therapy is available.

\section{Acknowledgements}

Leonard Da Silva and Ana Cristina Vargas are recipients of PhD Fellowships from the Ludwig Institute of Cancer Research. Leonard Da Silva is enrolled with the "Universidade Federal de São Paulo, Escola Paulista de Medicina, Curso de Pós-Graduação, Doutorado, Departamento de Anatomia Patológica, São Paulo, Brazil". Peter Simpson is a recipient of a fellowship from the National Breast Cancer Foundation. Georgia Chenevix-Trench and KumKum Khanna are Senior Principal Research Fellows of the NHMRC. RLB is a Cancer Institute NSW Fellow. We also acknowledge the help of staff within anatomical pathology, RBWH, Brisbane, the animal house facility at UQ AIBN, Brisbane, Casey Wright from the Thoracic Research Laboratory, School of Medicine, at the UQ, and Clay Winterford and his staff from the UQ/QIMR Histotechnology facility, and Macky Edmundson in the sequencing facility at QIMR. We would like to thank Sequenom Inc. for providing the primer sequences used for HRM, and, in particular, we thank Darryl Irwin for his help.

\section{Additional material}

\footnotetext{
Additional file 1: Supplementary methodologies. This file contains information of how the morphological review and TMA creation were performed. It also contains information on protocols for

immunohistochemistry and chromogenic in situ hybridization, RNA extraction and Real-Time RT-PCR, DASL gene expression profiling, cell

line analysis and culture, oncoCarta somatic mutation analysis protocols, high resolution melt analysis and iPLEX genotyping protocols.
} 
Additional file 2: Supplementary results. This file contains tables and figures regarding all immunohistochemistry data, extra gene expression and mutation results, and HER family gene expression by RT-PCR.

\section{Abbreviations}

CISH: chromogenic in situ hybridization; DASL: CDNA-mediated Annealing, Selection, extension, and Ligation; EGFR: epidermal growth factor receptor; ER: estrogen receptor; FFPE: formalin fixed-paraffin embedded; GEO: Gene Expression Omnibus; HER: human epidermal growth factor receptor; HRM: High Resolution Melt; IDC: invasive ductal carcinoma; MAPs: Mutant Allele Proportions; NSABP: National Surgical Adjuvant Breast and Bowel Project; NST: non-specific type; PgR: progesterone receptors.

\section{Author details}

${ }^{1}$ Molecular \& Cellular Pathology, The University of Queensland Centre for Clinical Research, \& School of Medicine, Building 918/B71, RBWH complex, Brisbane, 4029, Australia. ${ }^{2}$ Cancer Genetics and Molecular Pathology, The Queensland Institute of Medical Research, 300 Herston Road, Brisbane, 4006, Australia. ${ }^{3}$ Departamento de Anatomia Patológica, Universidade Federal de São Paulo, EPM, 754 Rua Napoleão de Barros, São Paulo, 04024-000, Brazil. ${ }^{4}$ Biomolecular and Biomedical Science, Griffith University, 170 Kessels Road, Brisbane, 4011, Australia. ${ }^{5}$ Centre for Magnetic Resonance, The University of Queensland, St Lucia, Brisbane, 4072, Australia. 'embaga Eijkman, Eijkman Institute, Diponegoro 69, Jakarta, 10430, Indonesia. ${ }^{7}$ Departamento de Patologia, Instituto Nacional de Câncer, 23 Praça Cruz Vermelha, Rio de Janeiro, 20230-130, Brazil. ${ }^{8}$ Departamento de Patologia, Laboratório Salomão \& Zoppi, 48 Rua Correia Dias, São Paulo, 04104-000, Brazil. ' Department of Pathology, Medical Faculty of Charles University in Plzen, Husova 3, 306 05, Czech Republic. ${ }^{10}$ Sydney West Area Health Service, Institute of Clinical Pathology and Medical Research, University of Sydney, Darcy Road, Sydney, 2145, Australia. ${ }^{11}$ Translational Oncology, Sydney West Area Health Service, Westmead Millennium Institute, University of Sydney, Darcy Road, Sydney, 2145, Australia. ${ }^{2}$ Department of Pathology, Peter MacCallum Cancer Centre, St Andrews Pl, East Melbourne, 3002, Australia. ${ }^{13}$ Queensland Brain Institute, The University of Queensland, St Lucia, Brisbane, 4072, Australia. ${ }^{14}$ Signal Transduction, The Queensland Institute of Medical Research, 300 Herston Road, Brisbane, 4006, Australia. ${ }^{15}$ Pathology Queensland: The Royal Brisbane \& Women's Hospital, Herston Road, Brisbane, 4029, Australia. ${ }^{16}$ Current address - University of Florida, McKnight Brain Institute,100 S. Newell Drive, Gainesville, 32611, USA.

\section{Authors' contributions}

LDS analysed the immunohistochemical markers, accrued and collated the data, carried out statistical and gene expression analysis and drafted the manuscript. PK and ACV analysed immunohistochemical markers, and accrued and collated the data. NW, CES and PTS supervised gene expression analyses and drafted the manuscript. $E P, P F, A S, M F, R B, M B$ and $M C$ identified patients with brain metastases in their institutions, collected samples and performed initial tumor classification. LR, SP, PK and AL performed immunohistochemistry and participated in the construction of TMAs. KK, NK, BJM and BR participated in the study design. SB, SH and JB performed mutation analyses. $H D, A D$ and SF performed validation of EGFR mutations. GCT and SRL conceived the study, supervised the experiments and drafted the manuscript.

\section{Competing interests}

Leonard Da Silva and Sunil Lakhani hold an USA registered patent relating to the data in this manuscript. All the other authors declare no conflict of interest.

Received: 14 March 2010 Revised: 15 June 2010 Accepted: 6 July 2010 Published: 6 July 2010

\section{References}

1. Lin NU, Bellon JR, Winer EP: CNS metastases in breast cancer. J Clin Oncol 2004, 22:3608-3617.
2. Weil RJ, Palmieri DC, Bronder JL, Stark AM, Steeg PS: Breast cancer metastasis to the central nervous system. Am J Pathol 2005, 167:913-920.

3. Hicks DG, Short SM, Prescott NL, Tarr SM, Coleman KA, Yoder BJ, Crowe JP, Choueiri TK, Dawson AE, Budd GT, Tubbs RR, Casey G, Weil RJ: Breast cancers with brain metastases are more likely to be estrogen receptor negative, express the basal cytokeratin CK5/6, and overexpress HER2 or EGFR. Am J Surg Pathol 2006, 30:1097-1104.

4. Shmueli E, Wigler N, Inbar M: Central nervous system progression among patients with metastatic breast cancer responding to trastuzumab treatment. Eur J Cancer 2004, 40:379-382.

5. Tham YL, Sexton K, Kramer R, Hilsenbeck S, Elledge R: Primary breast cancer phenotypes associated with propensity for central nervous system metastases. Cancer 2006, 107:696-704.

6. Arteaga CL: ErbB-targeted therapeutic approaches in human cancer. Exp Cell Res 2003, 284:122-130.

7. Hudis CA: Trastuzumab-mechanism of action and use in clinical practice. N Engl J Med 2007, 357:39-51.

8. Rakha EA, Reis-Filho JS, Ellis IO: Basal-like breast cancer: a critical review. J Clin Oncol 2008, 26:2568-2581.

9. Fulford LG, Reis-Filho JS, Ryder K, Jones C, Gillett CE, Hanby A, Easton D, Lakhani SR: Basal-like grade III invasive ductal carcinoma of the breast: patterns of metastasis and long-term survival. Breast Cancer Res 2007, 9: R4.

10. Luck AA, Evans AJ, Green AR, Rakha EA, Paish C, Ellis IO: The influence of basal phenotype on the metastatic pattern of breast cancer. Clin Oncol (R Coll Radiol) 2008, 20:40-45.

11. Paget $\mathrm{S}$ : The distribution of secondary growths in cancer of the breast. Cancer Metastasis Rev 1989, 8:98-101.

12. Minn AJ, Gupta GP, Siegel PM, Bos PD, Shu W, Giri DD, Viale A, Olshen AB, Gerald WL, Massague J: Genes that mediate breast cancer metastasis to lung. Nature 2005, 436:518-524.

13. Minn AJ, Kang Y, Serganova I, Gupta GP, Giri DD, Doubrovin M, Ponomarev V, Gerald WL, Blasberg R, Massague J: Distinct organ-specific metastatic potential of individual breast cancer cells and primary tumors. J Clin Invest 2005, 115:44-55.

14. Bos PD, Zhang XH, Nadal C, Shu W, Gomis RR, Nguyen DX, Minn AJ, van de Vijver MJ, Gerald WL, Foekens JA, Massagué J: Genes that mediate breast cancer metastasis to the brain. Nature 2009, 459:1005-1009.

15. Palmieri D, Bronder JL, Herring JM, Yoneda T, Weil RJ, Stark AM, Kurek R, Vega-Valle E, Feigenbaum L, Halverson D, Vortmeyer AO, Steinberg SM, Aldape K, Steeg PS: Her-2 overexpression increases the metastatic outgrowth of breast cancer cells in the brain. Cancer Res 2007, 67:4190-4198.

16. Wood LD, Parsons DW, Jones S, Lin J, Sjöblom T, Leary RJ, Shen D, Boca SM, Barber T, Ptak J, Silliman N, Szabo S, Dezso Z, Ustyanksky V, Nikolskaya T, Nikolsky Y, Karchin R, Wilson PA, Kaminker JS, Zhang Z, Croshaw R, Willis J, Dawson D, Shipitsin M, Willson JK, Sukumar S, Polyak K, Park BH, Pethiyagoda CL, Pant PV, et al: The genomic landscapes of human breast and colorectal cancers. Science 2007, 318:1108-1113.

17. Lin J, Gan CM, Zhang X, Jones S, Sjöblom T, Wood LD, Parsons DW, Papadopoulos N, Kinzler KW, Vogelstein B, Parmigiani G, Velculescu VE: A multidimensional analysis of genes mutated in breast and colorectal cancers. Genome Res 2007, 17:1304-1318.

18. Stephens PJ, McBride DJ, Lin ML, Varela I, Pleasance ED, Simpson JT, Stebbings LA, Leroy C, Edkins S, Mudie L, Greenman CD, Jia M, Latimer C, Teague JW, Lau KW, Burton J, Quail MA, Swerdlow H, Churcher C, Natrajan R, Sieuwerts AM, Martens JW, Silver DP, Langerød A, Russnes HE, Foekens JA, Reis-Filho JS, van't Veer L, Richardson AL, Børresen-Dale AL, et al: Complex landscapes of somatic rearrangement in human breast cancer genomes. Nature 2009, 462:1005-1010.

19. Hollestelle A, Nagel JH, Smid M, Lam S, Elstrodt F, Wasielewski M, Ng SS, French PJ, Peeters JK, Rozendaal MJ, Riaz M, Koopman DG, Ten Hagen TL, de Leeuw BH, Zwarthoff EC, Teunisse A, van der Spek PJ, Klijn JG, Dinjens WN, Ethier SP, Clevers H, Jochemsen AG, den Bakker MA, Foekens JA, Martens JW, Schutte M: Distinct gene mutation profiles among luminal-type and basal-type breast cancer cell lines. Breast Cancer Res Treat 2010, 121:53-64.

20. COSMIC - Catalogue of Somatic Mutations in Cancer. [http://www.sanger. ac.uk/genetics/CGP/cosmic/]. 
21. Hu X, Stern HM, Ge L, O'Brien C, Haydu L, Honchell CD, Haverty PM, Peters BA, Wu TD, Amler LC, Chant J, Stokoe D, Lackner MR, Cavet G: Genetic alterations and oncogenic pathways associated with breast cancer subtypes. Mol Cancer Res 2009, 7:511-522.

22. Hynes NE, Dey JH: PI3K inhibition overcomes trastuzumab resistance: blockade of ErbB2/ErbB3 is not always enough. Cancer Cell 2009, 15:353-355.

23. Junttila TT, Akita RW, Parsons K, Fields C, Lewis Phillips GD, Friedman LS, Sampath D, Sliwkowski MX: Ligand-independent HER2/HER3/PI3K complex is disrupted by trastuzumab and is effectively inhibited by the PI3K inhibitor GDC-0941. Cancer Cell 2009, 15:429-440.

24. Normanno N, Tejpar S, Morgillo F, De Luca A, Van Cutsem E, Ciardiello F: Implications for KRAS status and EGFR-targeted therapies in metastatic CRC. Nat Rev Clin Oncol 2009, 6:519-527.

25. Fan JB, Yeakley JM, Bibikova M, Chudin E, Wickham E, Chen J, Doucet D, Rigault P, Zhang B, Shen R, McBride C, Li HR, Fu XD, Oliphant A, Barker DL, Chee MS: A versatile assay for high-throughput gene expression profiling on universal array matrices. Genome Res 2004, 14:878-885.

26. Thomas RK, Baker AC, Debiasi RM, Winckler W, Laframboise T, Lin WM, Wang M, Feng W, Zander T, MacConaill L, Lee JC, Nicoletti R, Hatton C, Goyette M, Girard L, Majmudar K, Ziaugra L, Wong KK, Gabriel S, Beroukhim R, Peyton M, Barretina J, Dutt A, Emery C, Greulich H, Shah K, Sasaki H, Gazdar A, Minna J, Armstrong SA, et al: High-throughput oncogene mutation profiling in human cancer. Nat Genet 2007 , 39:347-351.

27. Krypuy M, Newnham GM, Thomas DM, Conron M, Dobrovic A: High resolution melting analysis for the rapid and sensitive detection of mutations in clinical samples: KRAS codon 12 and 13 mutations in nonsmall cell lung cancer. BMC Cancer 2006, 6:295

28. Yu J, Kane S, Wu J, Benedettini E, Li D, Reeves C, Innocenti G, Wetzel R, Crosby K, Becker A, Ferrante M, Cheung WC, Hong X, Chirieac LR, Sholl LM, Haack H, Smith BL, Polakiewicz RD, Tan Y, Gu TL, Loda M, Zhou X, Comb MJ: Mutation-specific antibodies for the detection of EGFR mutations in non-small-cell lung cancer. Clin Cancer Res 2009, 15:3023-3028.

29. Ellis IO, Schnitt SJ, Sastre-Garau X, Bussolati G, Tavassoli FA, Eusebi V, Peterse JL, Mukai K, Tabar L, Jacquemier J, et al: Invasive breast carcinomas. Pathology and Genetics of Tumours of the Breast and Female Genital Organs Lyon: IARC PressTavassoli FA, Devilee P 2003, 13-59.

30. DiGiovanna MP, Lerman MA, Coffey RJ, Muller WJ, Cardiff RD, Stern DF: Active signaling by Neu in transgenic mice. Oncogene 1998, 17:1877-1884.

31. Weigelt B, Hu Z, He X, Livasy C, Carey LA, Ewend MG, Glas AM, Perou CM, Van't Veer L: Molecular portraits and 70-gene prognosis signature are preserved throughout the metastatic process of breast cancer. Cancer Res 2005, 65:9155-9158.

32. Kao LS, Green CE: Analysis of variance: is there a difference in means and what does it mean? J Surg Res 2008, 144:158-170.

33. Schulze WX, Deng L, Mann M: Phosphotyrosine interactome of the ErbBreceptor kinase family. Mol Syst Biol 2005, 1:2005.

34. Law AJ, Shannon Weickert C, Hyde TM, Kleinman JE, Harrison PJ: Neuregulin-1 (NRG-1) mRNA and protein in the adult human brain. Neuroscience 2004, 127:125-136.

35. Pinkas-Kramarski R, Eilam R, Spiegler O, Lavi S, Liu N, Chang D, Wen D, Schwartz M, Yarden Y: Brain neurons and glial cells express Neu differentiation factor/heregulin: a survival factor for astrocytes. Proc Natl Acad Sci USA 1994, 91:9387-9391.

36. Gaedcke J, Traub F, Milde S, Wilkens L, Stan A, Ostertag H, Christgen M, von Wasielewski R, Kreipe $\mathrm{HH}$ : Predominance of the basal type and HER-2/neu type in brain metastasis from breast cancer. Mod Pathol 2007, 20:864-870.

37. Honeth G, Bendahl PO, Ringner M, Saal LH, Gruvberger-Saal SK, Lovgren K, Grabau D, Ferno M, Borg A, Hegardt C: The CD44+/CD24- phenotype is enriched in basal-like breast tumors. Breast Cancer Res 2008, 10:R53.

38. Al-Hajj M, Wicha MS, Benito-Hernandez A, Morrison SJ, Clarke MF: Prospective identification of tumorigenic breast cancer cells. Proc Natl Acad Sci USA 2003, 100:3983-3988.

39. Nandi $A$, Estess $P$, Siegelman $\mathrm{MH}$ : Hyaluronan anchoring and regulation on the surface of vascular endothelial cells is mediated through the functionally active form of CD44. J Biol Chem 2000, 275:14939-14948.
40. Al Qteishat A, Gaffney JJ, Krupinski J, Slevin M: Hyaluronan expression following middle cerebral artery occlusion in the rat. Neuroreport 2006, 17:1111-1114

41. Marangoni E, Lecomte N, Durand L, de Pinieux G, Decaudin D, Chomienne C, Smadja-Joffe F, Poupon MF: CD44 targeting reduces tumour growth and prevents post-chemotherapy relapse of human breast cancers xenografts. Br J Cancer 2009, 100:918-922.

42. Parker MW, Chen $Y$, Hallenbeck JM, Ford BD: Neuregulin expression after focal stroke in the rat. Neurosci Lett 2002, 334:169-172.

43. Wang GL, Semenza GL: Characterization of hypoxia-inducible factor 1 and regulation of DNA binding activity by hypoxia. J Biol Chem 1993, 268:21513-21518.

44. Sun M, Behrens C, Feng L, Ozburn N, Tang X, Yin G, Komaki R, VarellaGarcia M, Hong WK, Aldape KD, Wistuba II: HER family receptor abnormalities in lung cancer brain metastases and corresponding primary tumors. Clin Cancer Res 2009, 15:4829-4837.

45. Konecny GE, Pegram MD, Venkatesan N, Finn R, Yang G, Rahmeh M, Untch M, Rusnak DW, Spehar G, Mullin RJ, Keith BR, Gilmer TM, Berger M, Podratz KC, Slamon DJ: Activity of the dual kinase inhibitor lapatinib (GW572016) against HER-2-overexpressing and trastuzumab-treated breast cancer cells. Cancer Res 2006, 66:1630-1639.

46. Berger MB, Mendrola JM, Lemmon MA: ErbB3/HER3 does not homodimerize upon neuregulin binding at the cell surface. FEBS Lett 2004, 569:332-336

47. S Paik CK, Jeong J, Geyer CE, Romond EH, Mejia-Mejia O, Mamounas EP: Benefit from adjuvant trastuzumab may not be confined to patients with IHC 3+ and/or FISH-positive tumors: Central testing results from NSABP B-31. ASCO Annual Meeting Proceedings (Post-Meeting Edition), Journal of Clinical Oncology 2007, 25(18S):511.

48. de Alava E, Ocana A, Abad M, Montero JC, Esparis-Ogando A, Rodriguez CA, Otero AP, Hernandez T, Cruz JJ, Pandiella A: Neuregulin expression modulates clinical response to trastuzumab in patients with metastatic breast cancer. J Clin Oncol 2007, 25:2656-2663.

49. Agus DB, Akita RW, Fox WD, Lewis GD, Higgins B, Pisacane PI, Lofgren JA, Tindell C, Evans DP, Maiese K, Scher HI, Sliwkowski MX: Targeting ligandactivated ErbB2 signaling inhibits breast and prostate tumor growth. Cancer Cell 2002, 2:127-137.

50. MacConaill LE, Campbell CD, Kehoe SM, Bass AJ, Hatton C, Niu L, Davis M, Yao K, Hanna M, Mondal C, Luongo L, Emery CM, Baker AC, Philips J, Goff DJ, Fiorentino M, Rubin MA, Polyak K, Chan J, Wang Y, Fletcher JA, Santagata S, Corso G, Roviello F, Shivdasani R, Kieran MW, Ligon KL, Stiles CD, Hahn WC, Meyerson ML, et al: Profiling critical cancer gene mutations in clinical tumor samples. PLoS One 2009, 4:e7887.

51. Romero PA, Arnold FH: Exploring protein fitness landscapes by directed evolution. Nat Rev Mol Cell Biol 2009, 10:866-876.

52. Meylan E, Dooley AL, Feldser DM, Shen L, Turk E, Ouyang C, Jacks T: Requirement for NF-kappaB signalling in a mouse model of lung adenocarcinoma. Nature 2009, 462:104-107.

53. Ding L, Ellis MJ, Li S, Larson DE, Chen K, Wallis JW, Harris CC, McLellan MD Fulton RS, Fulton LL, Abbott RM, Hoog J, Dooling DJ, Koboldt DC, Schmidt H, Kalicki J, Zhang Q, Chen L, Lin L, Wendl MC, McMichael JF, Magrini VJ, Cook L, McGrath SD, Vickery TL, Appelbaum E, Deschryver K, Davies $S$, Guintoli T, Lin L, et al: Genome remodelling in a basal-like breast cancer metastasis and xenograft. Nature 2010, 464:999-1005.

54. Shah SP, Morin RD, Khattra J, Prentice L, Pugh T, Burleigh A, Delaney A, Gelmon K, Guliany R, Senz J, Steidl C, Holt RA, Jones S, Sun M, Leung G, Moore R, Severson T, Taylor GA, Teschendorff AE, Tse K, Turashvili G, Varhol R, Warren RL, Watson P, Zhao Y, Caldas C, Huntsman D, Hirst M, Marra MA, Aparicio S: Mutational evolution in a lobular breast tumour profiled at single nucleotide resolution. Nature 2009, 461:809-813.

55. Ellis IO, Schnitt SJ, Sastre-Garau X, et al: Invasive breast carcinomas. Pathology and Genetics of Tumours of the Breast and Female Genital Organs Lyon: IARC PressTavassoli FA, Devilee P 2003, 13-59.

56. Bibikova M, Talantov D, Chudin E, Yeakley JM, Chen J, Doucet D, Wickham E, Atkins D, Barker D, Chee M, Wang Y, Fan JB: Quantitative gene expression profiling in formalin-fixed, paraffin-embedded tissues using universal bead arrays. Am J Pathol 2004, 165:1799-1807.

57. Fan JB, Yeakley JM, Bibikova M, Chudin E, Wickham E, Chen J, Doucet D, Rigault P, Zhang B, Shen R, McBride C, Li HR, Fu XD, Oliphant A, Barker DL, 
Chee MS: A versatile assay for high-throughput gene expression profiling on universal array matrices. Genome Res 2004, 14:878-885.

58. Da Silva L, Parry S, Reid L, Keith P, Waddell N, Kossai M, Clarke C,

Lakhani SR, Simpson PT: Aberrant expression of E-cadherin in lobular carcinomas of the breast. Am J Surg Pathol 2008, 32:773-783.

59. Kramer D, Thunnissen FB, Gallegos-Ruiz MI, Smit EF, Postmus PE, Meijer CJ, Snijders PJ, Heideman DA: A fast, sensitive and accurate high resolution melting (HRM) technologybased assay to screen for common K-ras mutations. Cellular Oncology 2009, 31:161-167.

doi:10.1186/bcr2603

Cite this article as: Da Silva et al.: HER3 and downstream pathways are involved in colonization of brain metastases from breast cancer. Breast Cancer Research 2010 12:R46.

\section{Submit your next manuscript to BioMed Central} and take full advantage of:

- Convenient online submission

- Thorough peer review

- No space constraints or color figure charges

- Immediate publication on acceptance

- Inclusion in PubMed, CAS, Scopus and Google Scholar

- Research which is freely available for redistribution

Submit your manuscript at www.biomedcentral.com/submit 